\title{
HYDROGEN SULFIDE: UK OCCUPATIONAL EXPOSURE LIMITS
}

Michael G Costigan

Occup Environ Med 2003;60:308-312

ydrogen sulfide $\left(\mathrm{H}_{2} \mathrm{~S}\right)$ is a toxic gas with an offensive odour reminiscent of rotten eggs. There is the potential for widespread occupational exposure to $\mathrm{H}_{2} \mathrm{~S}$, including in the oil and water

treatment industries. There is a particular concern for exposure in confined spaces such as manholes and sewer pipes; the high concentrations that can build up in such conditions (> 1000 parts per million (ppm)) can lead to the rapid development (within minutes) of unconsciousness and death. There are many reports throughout the literature of fatalities caused by exposure to $\mathrm{H}_{2} \mathrm{~S}$. However, there is also a concern for adverse health effects caused by day to day occupational exposures to low concentrations $(<10 \mathrm{ppm})$; this is because $\mathrm{H}_{2} \mathrm{~S}$ selectively binds to the enzymes involved in cellular respiration thereby causing a shift towards anaerobic respiration. The recently revised UK occupational exposure limits for $\mathrm{H}_{2} \mathrm{~S}$ are designed to protect against the development of such effects.

\section{SETTING OCCUPATIONAL EXPOSURE LIMITS FOR $\mathrm{H}_{2} \mathrm{~S}$}

The purpose of this paper is to outline the evidence and rationale underpinning the recently updated UK occupational exposure limits (OELs) for $\mathrm{H}_{2} \mathrm{~S}$. To place this information in context it is helpful to have an understanding of the UK regulatory framework surrounding OELs. A previous paper in this series has already covered this topic. ${ }^{1}$ Box 1 and fig 1 summarise the key features involved in OEL setting in the UK. The reason why the OELs for $\mathrm{H}_{2} \mathrm{~S}$ were recently reviewed in the UK is because in the mid 1990s a series of human volunteer studies were published that suggested exposures as low as $10 \mathrm{ppm}$ might cause a shift to anaerobic metabolism under conditions of physical exertion. This leads to a concern for adverse physiological effects at what were at the time the existing occupational exposure standard (OES) values for $\mathrm{H}_{2} \mathrm{~S}$ of $10 \mathrm{ppm}$ ( 8 hour time weighted average (TWA)) and $15 \mathrm{ppm}$ (short term exposure limit (STEL)). Given that there are thousands of workers exposed to $\mathrm{H}_{2} \mathrm{~S}$ in the UK, this substance was viewed as a priority for review in the OEL programme via the Working Group on the Assessment of Toxic Chemicals/Advisory Committee on Toxic Substances (WATCH/ACTS) system.

Once it has been decided to place a chemical on the UK OEL review programme, a multidisciplinary team from the UK Health and Safety Executive (HSE) assembles a scientific and technical package that will go forward for evaluation at WATCH. The components of the HSE package on $\mathrm{H}_{2} \mathrm{~S}$ summarised in this paper are the toxicology (including human epidemiology) and the occupational hygiene assessments. The HSE toxicology assessment was based partly on a 1992 Criteria Document $^{2}$ commissioned by the European Directorate responsible for worker health, supplemented by a full literature search to identify studies published after 1992. The occupational hygiene assessment was based on an HSE survey of the industrial uses and exposures to $\mathrm{H}_{2} \mathrm{~S}$ across UK industry.

The published literature on $\mathrm{H}_{2} \mathrm{~S}$ goes back over many years. From this, longstanding beliefs and assumptions have been perpetuated regarding the toxic effects of $\mathrm{H}_{2} \mathrm{~S}$. For example, the impression is given that $\mathrm{H}_{2} \mathrm{~S}$ is a very irritant gas, and has also been associated with a phenomenon known as "gas eye". However, as can be seen from the following critical scientific evidence of the toxicity data, beliefs such as these turn out not to be particularly well supported by hard data.

\section{OVERVIEW OF INDUSTRIAL EXPOSURES TO $\mathrm{H}_{2} \mathrm{~S}$}

$\mathrm{H}_{2} \mathrm{~S}$ is produced from the anaerobic decomposition of animal and vegetable waste-for example, in slurry and manure storage pits, in effluent waste and sewage. The gas is a natural component of petroleum and of natural gas where it is known as "sour gas" (table 1).

There is no commercial production of $\mathrm{H}_{2} \mathrm{~S}$ or any recovery of the gas from natural sources within

Correspondence to: Dr MG Costigan, Health and Safety Executive, Room 211 , Magdalen House, Trinity Road, Bootle, Merseyside L20 3QZ, UK;

michael.costigan@hse.gsi.gov.uk the UK for distribution and/or use. All of the $\mathrm{H}_{2} \mathrm{~S}$ utilised in UK industry is imported. $\mathrm{H}_{2} \mathrm{~S}$ is produced as a byproduct during the manufacture of viscose rayon, synthetic rubber compounds, and phosphorus pentasulfide. The gas is also released during petroleum refining operations.

Large amounts of liquefied $\mathrm{H}_{2} \mathrm{~S}$ are imported into the UK for use in the production of dyes, chemical intermediates, and pharmaceuticals. There is also some specialised use of the liquefied gas in the treatment of metals and in research and quality control establishments. 


\section{Box 1: Occupational exposure limits (OELs)}

- In the UK, the Control of Substances Hazardous to Health Regulations (COSHH) 1988 provides the legal basis for OELS

- OELs refer to airborne concentrations of a substance measured over a specified time period, either an 8 hour time weighted average (TWA) and/or a 15 minute reference period. The latter is referred to as a short term exposure limit (STEL)

- STELs are applied to substances capable of causing immediate health effects following brief peaks of exposure. Typically, such effects would be sensory irritation of the eyes and respiratory tract, or central nervous system (CNS) depression, or acute lethality (for example, as with hydrogen cyanide or phosgene). In contrast, OELs (8 hour TWA) are aimed at controlling against the more slowly developing effects of long term repeated exposures

- In the UK, OELs are set by the Health and Safety Commission on advice from its Advisory Committee on Toxic Substances (ACTS), which in turn takes advice from its scientific subcommittee known as the Working Group on the Assessment of Toxic Chemicals (WATCH)

- Under the UK COSHH Regulations there are two types of OEL. These are occupational exposure standards (OESs) and maximum exposure limits (MELs)

- OESs represent exposures that, according to available scientific knowledge, will not cause any injury to health and which are also reasonably practicable for industry to achieve

- MELs are applied to substances with serious health concerns (typically carcinogens and asthmagens) for which it is not always possible to identify a threshold level of exposure below which there would be no residual risk to health. Alternatively, a threshold may be identifiable but industry is unable to control exposures to below this threshold. For these reasons, the legal duty associated with MELs requires that employers reduce exposure to as low as is reasonably practicable below the value of the MEL

In the UK, around 125000 workers are potentially exposed to $\mathrm{H}_{2} \mathrm{~S}$ in work related to the treatment of sewage, effluent waste, and farm slurry. In the offshore oil and gas industries about 3000 workers are potentially exposed.

HSE's survey of occupational exposures revealed that most exposures to $\mathrm{H}_{2} \mathrm{~S}$ in the offshore oil and gas industry are generally below 5 ppm ( 8 hour TWA) and 10 ppm ( 15 minute reference period). In effluent waste and sewage treatment, and work on landfill sites, most exposures are below 5 ppm ( 8 hour TWA). However, concentrations up to $600 \mathrm{ppm}$ were recorded at the base of a sump tank and concentrations $>300 \mathrm{ppm}$ were measured in a settlement tank. Under normal handling of farm slurry personal exposures to $\mathrm{H}_{2} \mathrm{~S}$ should be below $5 \mathrm{ppm}$ ( 8 hour TWA) and $10 \mathrm{ppm}$ ( 15 minute reference period). However, HSE recorded high concentrations of $\mathrm{H}_{2} \mathrm{~S}$ of up to 1000 ppm during the mixing of farm slurry. Also, high exposures to $\mathrm{H}_{2} \mathrm{~S}$ exceeding 2000 ppm can occur when working in manholes, drains, sewers, and other confined spaces.

\section{TOXICOLOGICAL PROFILE OF $\mathrm{H}_{2} \mathrm{~S}$ \\ Toxicokinetics}

$\mathrm{H}_{2} \mathrm{~S}$ is rapidly absorbed from the lungs following inhalation exposure. Absorption of the gas through the skin is minimal. ${ }^{2}$ Following absorption, $\mathrm{H}_{2} \mathrm{~S}$ is widely distributed around the body, primarily as undissociated $\mathrm{H}_{2} \mathrm{~S}$ or as $\mathrm{HS}^{-}$ions. $\mathrm{H}_{2} \mathrm{~S}$ binds

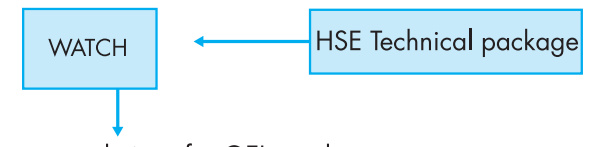

Recommendations for OELs and

other risk management measures

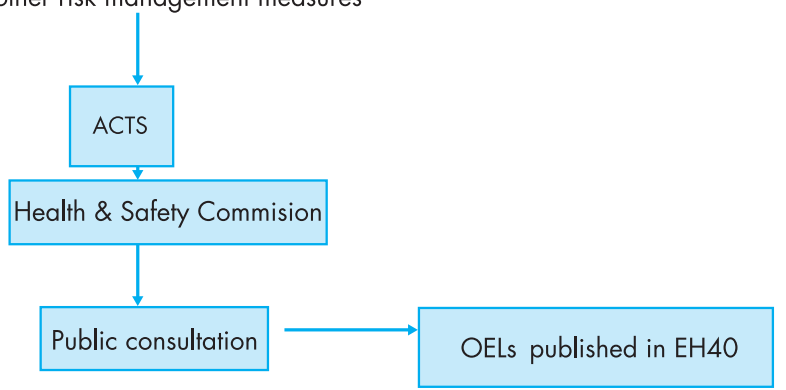

Figure 1 UK occupational exposure limit (OEL) setting process. ACTS, Advisory Committee on Toxic Substances; HSE, Health and Safety Executive; WATCH, Working Group on the Assessment of Toxic Chemicals.

reversibly to metalloenzymes, including those involved in aerobic cellular respiration such as cytochrome oxidase.

The main detoxification pathway for $\mathrm{H}_{2} \mathrm{~S}$ is oxidation to sulfate, occurring primarily in the liver and to a lesser extent in the blood, followed by excretion in the urine in free or conjugated form. Another minor metabolic route for $\mathrm{H}_{2} \mathrm{~S}$, occurring primarily in the intestinal mucosa and liver, is methylation to methanethiol and dimethylsulfide. Metabolism to sulfate is relatively rapid and hence $\mathrm{H}_{2} \mathrm{~S}$ is unlikely to bioaccumulate.

\section{Effects of single exposure}

The literature contains many case reports of fatal poisonings in workers exposed to $\mathrm{H}_{2} \mathrm{~S}$; the data clearly indicate that short term single exposures to concentrations of $500 \mathrm{ppm}$ and above may be fatal. ${ }^{3}$ Studies in animals confirm the human evidence regarding the acute toxicity of $\mathrm{H}_{2} \mathrm{~S}$. An $\mathrm{LC}_{50}$ (concentration causing lethality in $50 \%$ of animals) of $444 \mathrm{ppm}$ was measured in rats following a four hour exposure period. ${ }^{2}$ Human evidence suggests that exposure to higher concentrations, in the region of $1000 \mathrm{ppm}$ and above, causes death very rapidly (within minutes). Deaths at such high exposure concentrations are caused by inhibition of cytochrome oxidase; this causes a blockage of the mitochondrial electron transport system, and an inhibition of cellular respiration. This leads to inactivation of the respiratory centres in the brain, leading to respiratory arrest, unconsciousness, and death. In addition, more prolonged exposures to somewhat lower concentrations can cause severe pulmonary oedema and congestion which can also lead to death. Hence, there is a duality of the mechanisms leading to death involving both centrally mediated respiratory depression and lung damage. The relative significance of these mechanisms depends on the exposure conditions. Neurological sequelae, such as memory loss, are common in survivors following periods of unconsciousness caused by $\mathrm{H}_{2} \mathrm{~S}$ exposure. $^{2}$

A recent series of human volunteer studies involving short term exposures to $\mathrm{H}_{2} \mathrm{~S}$ demonstrated that exposure during exercise may cause a shift to anaerobic respiration ${ }^{4-8}$; blood lactate concentrations were found to increase following maximal exercise at $5 \mathrm{ppm}$ and submaximal exercise at $10 \mathrm{ppm}$, and there was some evidence to suggest that enzymes involved in aerobic metabolism, such as cytochrome oxidase in muscle tissue, were inhibited by $\mathrm{H}_{2} \mathrm{~S}$. However, despite these effects, 
Table 1 Exposures to hydrogen sulfide

\begin{tabular}{lll}
\hline Emissions from natural sources & Industrial byproduct emissions & Industrial uses \\
\hline $\begin{array}{lll}\text { Anaerobic decomposition of } \\
\text { vegetable/animal matter in slurry }\end{array}$ & $\begin{array}{l}\text { Emitted during manufacture of: } \\
\text {-viscose rayon }\end{array}$ & $\begin{array}{l}\text { Manufacture of sulfuric acid and } \\
\text { other sulfur compounds }\end{array}$ \\
$\begin{array}{l}\text { and manure storage pits, in effluent } \\
\text {-synthetic rubber compounds }\end{array}$ & $\begin{array}{l}\text { Liquefied gas used in the } \\
\text { manufacture of pharmaceuticals, } \\
\text {-phosphorous pentasulfide }\end{array}$ & $\begin{array}{l}\text { dyes, chemical intermediates, } \\
\text { heavy water, and refining of } \\
\text { metals, particularly copper }\end{array}$ \\
$\begin{array}{l}\text { and sulfurated spring waters } \\
\text { A component of petroleum and }\end{array}$ & $\begin{array}{l}\text { Used in research and quality } \\
\text { natural gas where it is known as }\end{array}$ & $\begin{array}{l}\text { control laboratories } \\
\text { "sour gas" }\end{array}$ \\
$\begin{array}{l}\text { Released during the drilling of gas } \\
\text { wells, and well testing operations }\end{array}$ &
\end{tabular}

the volunteers (fit, healthy young adults) did not report any accompanying adverse symptoms such as fatigue, nausea or headache. Whether or not older less fit adults would have experienced adverse symptoms under equivalent exposure conditions is unknown. Furthermore, the exposures to $\mathrm{H}_{2} \mathrm{~S}$ typically were of 30 minutes duration only, and the effects of more prolonged exposures are again unknown.

Exposures to high (near lethal) concentrations of $\mathrm{H}_{2} \mathrm{~S}$ also cause direct damage to the upper respiratory tract epithelium. Inhalation studies in rats showed that a four hour exposure to 400 ppm caused cell death and hair loss of the nasal and respiratory epithelium, with indications that an inflammatory response was occurring. ${ }^{90}$ However, below 200 ppm, these effects were only minimal. Exposure of rats to $50 \mathrm{ppm}$, but not $10 \mathrm{ppm}$, for four hours caused inhibition of lung cytochrome oxidase. ${ }^{11}$ It seems possible that the inhibition of lung cytochrome oxidase may possibly account for the pulmonary oedema observed at high exposure concentrations in animals and humans.

It is well documented that following high acute exposures to irritant gases-for example, sulfur dioxide-there can be residual bronchial hypersensitivity. However, HSE is not aware of any work carried out to investigate this phenomenon following exposures to $\mathrm{H}_{2} \mathrm{~S}$ alone.

\section{"Gas eye"}

There are many reports throughout the literature describing eye irritation in both humans and animals exposed to $\mathrm{H}_{2} \mathrm{~S}^{2{ }^{3}}$ Most of these reports are old and the exposure conditions were not always well defined. Several early studies from the viscose-rayon industry suggest that occupational exposures to relatively low concentrations of $\mathrm{H}_{2} \mathrm{~S}$ can cause a form of eye damage, "keratitis superficialis punctatis", commonly known as "gas eye" or "spinners eye". However, work in this industry also involves exposure to other substances such as carbon disulfide and acid gases such as sulfur dioxide as well as acid mists from sulfuric acid. It has been suggested that exposure to other agents may "sensitise" the eyes to the subsequent effects of $\mathrm{H}_{2} \mathrm{~S}^{12}$

A cross sectional epidemiological study was conducted in workers from a Belgian viscose-rayon factory has recently been published. ${ }^{13}$ Subjective reports of eye effects such as eye pain, eye burning, seeing coloured halos, photophobia, and hazy sight were assessed by questionnaire. In addition, ophthalmological examinations were conducted on all subjects. Measurements of personal exposures to carbon disulfide and $\mathrm{H}_{2} \mathrm{~S}$ were carried out. Exposures to carbon disulfide were above $10 \mathrm{ppm}$ in the majority of jobs. Exposures to $\mathrm{H}_{2} \mathrm{~S}$ ranged between 0.14-6.4 ppm with the highest exposures being in areas with the highest exposures to carbon disulfide. There were no detectable amounts of sulfuric acid in the air in this factory. The results showed a high correlation between combined exposure to carbon disulfide and $\mathrm{H}_{2} \mathrm{~S}$, and the prevalences of eye complaints. No subjects were exposed to $\mathrm{H}_{2} \mathrm{~S}$ alone, and the statistical analysis was unable to distinguish the separate effects of these gases. However, the study did demonstrate that exposures up to $4 \mathrm{ppm} \mathrm{H}_{2} \mathrm{~S}$, even in the presence of 29 ppm carbon disulfide, did not cause any eye effects.

There are studies that do not seem to support the view that $\mathrm{H}_{2} \mathrm{~S}$ causes "gas eye". In a study in rats and mice, involving specific ophthalmological tests, no signs of eye irritation were observed following 90 days of repeated exposures (six hours/ day) to $80 \mathrm{ppm} .{ }^{14}$ Similarly, in a separate study in rats only, no eye damage was observed following exposures up to $100 \mathrm{ppm}$ $\mathrm{H}_{2} \mathrm{~S}$ for three hours/day for five consecutive days. ${ }^{15}$

Clearly, work in viscose-rayon manufacture has been associated with "gas eye", but a specific causal role for $\mathrm{H}_{2} \mathrm{~S}$ in the development of this condition is an area of uncertainty. Animal evidence convincingly demonstrates a lack of ability to cause eye irritation following repeated exposures to $\mathrm{H}_{2} \mathrm{~S}$ alone at concentrations up to $100 \mathrm{ppm}$. This makes it seem very unlikely that exposures to $\mathrm{H}_{2} \mathrm{~S}$ at concentrations of current occupational relevance could be a cause of eye irritation. However, eye irritation has been reported in a number of early acute lethality studies in animals with $\mathrm{H}_{2} \mathrm{~S}$ and has also been reported in humans exposed to concentrations in the region of $500 \mathrm{ppm} .^{3}$ Overall, the balance of evidence suggests that eye irritation is a phenomenon only associated with high exposures to $\mathrm{H}_{2} \mathrm{~S}$, in the hundreds of ppm.

\section{Effects of repeated exposure}

Only a limited amount of information is available concerning the effects of repeated exposures to $\mathrm{H}_{2} \mathrm{~S}$. A cross sectional study in Finnish pulp mill workers showed no effects on pulmonary function (forced expiratory volume in one second $\left(\mathrm{FEV}_{1}\right)$ and forced vital capacity $\left.(\mathrm{FVC})\right)$ or on bronchial reactivity to histamine challenge with exposures of nonasthmatics to $\mathrm{H}_{2} \mathrm{~S}$ in the region of $2-7 \mathrm{ppm} .{ }^{16} \mathrm{~A}$ cross sectional study in US sewer workers employed for up to 20 years suggested a reduced pulmonary function in these workers compared to a referent group. However, there were no quantitative measures of $\mathrm{H}_{2} \mathrm{~S}$ exposure in the sewer workers. ${ }^{17} \mathrm{~A}$ study in Japanese workers from three viscose-rayon plants showed no evidence for effects on pulmonary function or on the reporting of respiratory symptoms; workers were exposed to mean concentrations of $\mathrm{H}_{2} \mathrm{~S}$ of 3 ppm. ${ }^{18}$ 
A couple of studies of individuals exposed environmentally or occupationally to $\mathrm{H}_{2} \mathrm{~S}$ suggested a variety of medical and neurophysiological effects. ${ }^{19} 20$ However, the individuals involved had all received confounding exposures to a range of chemicals, and in one study were all involved in litigation proceedings. Some of the subjects had been previously rendered unconscious by single high exposures to $\mathrm{H}_{2} \mathrm{~S}$ which may well have led to neurological sequelae. No reliable conclusions concerning the effects of repeated exposure to $\mathrm{H}_{2} \mathrm{~S}$ could be drawn from these studies.

A recent study in workers from a viscose-rayon factory did not show any link between exposure to $\mathrm{H}_{2} \mathrm{~S}$ and the development of neuropsychological effects. ${ }^{21}$ In this factory, workers received combined exposures to carbon disulfide ( $1-37 \mathrm{ppm}$ ) and up to $6 \mathrm{ppm} \mathrm{H}_{2} \mathrm{~S}$. Another recent study investigated the potential effects of $\mathrm{H}_{2} \mathrm{~S}$ on olfaction. ${ }^{22}$ The eight subjects of the study complained of problems related to the sense of smell following exposures to $\mathrm{H}_{2} \mathrm{~S} 2-3$ years previously. Four of the subjects had been rendered unconscious for several minutes. Sense of smell was assessed by questionnaire and by a standard battery of smell tests. Although all subjects reported smell dysfunction, the objective tests revealed normal olfactory function in all eight. HSE felt that no firm conclusions could be drawn from this isolated study. Given that high exposures to $\mathrm{H}_{2} \mathrm{~S}$ have been shown to cause nasal epithelial cell damage in animals, and human survivors of high exposure have shown neurological sequelae, it seems plausible that periods of high exposure would have the potential to cause an impairment in olfaction.

There is some evidence concerning the effects of repeated exposure to $\mathrm{H}_{2} \mathrm{~S}$ from animal studies. In brief, the most useful data derive from a good quality 90 day inhalation study in rats and mice. This study included detailed neurological and pathological examinations. The results demonstrated overt toxicity including deaths and inflammation in the nasal mucosa in mice, but not rats, following exposure to $80 \mathrm{ppm}$ $\mathrm{H}_{2} \mathrm{~S}$ for 90 days. No systemic or local signs of toxicity occurred in either species at $30 \mathrm{ppm} .{ }^{14}$ Hence, $30 \mathrm{ppm}$ would appear to be a "no observed adverse effect level" (NOAEL) for the effects of repeated exposure to $\mathrm{H}_{2} \mathrm{~S}$ in animals.

\section{Mutagenicity and carcinogenicity}

No studies into the mutagenic or carcinogenic potential of $\mathrm{H}_{2} \mathrm{~S}$ were located. However, a study in which rats were orally dosed with sodium sulfide for 78 weeks did not present any evidence of carcinogenicity. ${ }^{2}$ This provides some limited reassurance that $\mathrm{H}_{2} \mathrm{~S}$ is unlikely to be carcinogenic.

\section{Reproductive toxicity}

There are no studies in humans concerning the potential reproductive effects of $\mathrm{H}_{2} \mathrm{~S}$. In animals, no fertility studies were located. However, a number of developmental toxicity studies were located although the design of these studies did not conform to standard regulatory protocols. The results did not reveal any effects on fetal mortality or incidence of malformations or morphological variations ${ }^{23}{ }^{24}$; the only finding was altered concentrations of the amino acid neurotransmitters glutamate, aspartate, and GABA in the offspring of rats exposed to $75 \mathrm{ppm}$ during gestation and for 21 days postpartum. The interpretation of these findings is unclear but they are not regarded as providing clear evidence of overt developmental toxicity.

\section{BASIS FOR UK OELS}

WATCH concluded that the recent series of studies in human volunteers were key studies of relevance to the potential effects

\section{Box 2: Hydrogen sulfide-key points}

- Hydrogen sulfide $\left(\mathrm{H}_{2} \mathrm{~S}\right)$ is a colourless, flammable gas

- $\mathrm{H}_{2} \mathrm{~S}$ has a pungent odour reminiscent of rotten eggs. The odour is detectable at very low concentrations; the threshold for perception is between 0.02-0.13 ppm

- But! Odour perception is unreliable as a warning of high exposures; olfactory fatigue may develop at concentrations of $100 \mathrm{ppm}$ and above

- $\mathrm{H}_{2} \mathrm{~S}$ is a metabolic poison; it blocks the electron transport chain in mitochondria, inhibiting cellular utilisation of oxygen

- Exposures for a few hours to concentrations of 500 ppm and above are likely to be fatal. Exposure for a few minutes to concentrations of $1000 \mathrm{ppm}$ and above are likely to cause rapid unconsciousness and death. At higher concentrations, death is caused by depression of respiratory centres in the brain; at lower concentrations, death is caused by pulmonary oedema and congestion. The relative importance of each mechanism depends on the exposure conditions. Many fatalities have occurred in workers exposed in confined spaces such as manholes. Survivors of periods of unconsciousness may suffer permanent neurological sequelae such as memory loss. High exposures to near lethal concentrations in animals have shown destruction of nasal epithelium

- During vigorous exercise, low level exposures (5-10 ppm) cause a shift to anaerobic respiration, leading to increased lactic acid formation

- Evidence on eye irritation is inconsistent. The balance of evidence suggests that eye irritation is only likely to occur at high exposure concentrations, in region of hundreds of ppm

- In the UK, control of inhalation exposure to $\mathrm{H}_{2} \mathrm{~S}$ in the workplace must comply with occupational exposure standards (OESs) of 5 ppm (8 hour TWA) and 10 ppm (STEL). These values replace the previous OESs of 10 ppm (8 hour TWA) and $15 \mathrm{ppm}$ (STEL)

- The treatment of victims of $\mathrm{H}_{2} \mathrm{~S}$ poisoning is similar to that used for hydrogen cyanide poisoning. It involves parenteral administration of a methaemoglobin inducing agent such as sodium nitrite. Methaemoglobin binds with $\mathrm{HS}^{-}$ions to form sulfamethaemoglobin, and thus restores the activity of the sulfide inhibited cytochrome oxidase enzyme.

of occupational exposure. The findings from these studies demonstrate that brief periods (15-30 minutes) of exposure to 5 and $10 \mathrm{ppm}$, while undergoing maximal and submaximal exercise, respectively, cause a shift towards anaerobic respiration. No symptoms such as fatigue or muscle pain were reported as a consequence of these exposures. The effects of more prolonged exposures on metabolism are uncertain, although workers would be unlikely to maintain such high levels of physical exertion for substantial periods of time. However, the volunteers were all young fit healthy adults, and the worker population would include older and less fit subjects. It was also noted that a NOAEL of $30 \mathrm{ppm}$ was available from a repeated exposure study in rats and mice; there were no signs of any systemic target organ toxicity or local effects on the eyes or respiratory tract at this concentration.

Taking all of these factors into consideration, together with knowledge of the exposure concentrations that occur in industry, WATCH considered that $\mathrm{H}_{2} \mathrm{~S}$ met the criteria for the establishment of an OES. WATCH recommended that an OES of 5 ppm ( 8 hour TWA) would be appropriate; in addition, WATCH felt that in view of the acute toxicity of $\mathrm{H}_{2} \mathrm{~S}$, a STEL was necessary to emphasise the need to control short term 
peak exposures. Consideration of the human and animal evidence suggested that a STEL OES of $10 \mathrm{ppm}$ would be appropriate. In reaching its decision, WATCH agreed that from the occupational hygiene data available, it would be reasonably practicable for UK industry to achieve control to these levels.

In relation to other possible risk management measures

that can accompany OELs, WATCH noted that as there was no evidence for the ability of $\mathrm{H}_{2} \mathrm{~S}$ to induce occupational asthma, a "sensitising notation" should not be applied. Given that skin absorption of $\mathrm{H}_{2} \mathrm{~S}$ is considered to be negligible, a "skin notation" is not considered appropriate. Finally, exposure to $\mathrm{H}_{2} \mathrm{~S}$ can be assessed from measurements of sulfide in blood or thiosulfate in urine. Such measurements tend to have been taken only for acute exposure incidents, and not as a routine in the workplace. However, the fact that $\mathrm{H}_{2} \mathrm{~S}$ is not absorbed via the skin, and that respiratory protective equipment is not routinely used in workers exposed to $\mathrm{H}_{2} \mathrm{~S}$, meant that the UK criteria for establishing a biological monitoring standard were not met. Hence, WATCH did not recommend the setting of a biological monitoring standard for $\mathrm{H}_{2} \mathrm{~S}$.

These recommendations from WATCH were subsequently endorsed by ACTS, and are now listed in the HSE publication EH40/2002..$^{25}$ A summary document giving details of the basis for the UK limits will also be available during 2002 as part of the EH64 series. ${ }^{26}$

\section{REFERENCES}

1 Topping M. Occupational exposure limits for chemicals. Occup Environ Med 2001;58:138-44.

- This paper explains the processes by which occupational exposure limits are set within the UK.

2 Health and Safety Executive. DGV Criteria Document. Scientific expert group on occupational exposure limits - hydrogen sulphide. SEG/CDO/40, 1992

- This document formed part of the basis for the HSE review of the toxicology assessment of $\mathrm{H}_{2} \mathrm{~S}$.

3 Turner RM, Fairhurst S. Toxicology of substances in relation to major hazards: hydrogen sulphide. London: HSE Books, 1990.

- This monograph provides a good overview of the acute toxicity of $\mathrm{H}_{2} \mathrm{~S}$.

4 Bhambhani Y, Singh M. Physiological effects of hydrogen sulfide inhalation during exercise in healthy men. J Appl Physiol $1991 ; 71: 1872-7$.

- This paper and the following papers by the same authors (references 5-8) contain the key human data upon which the UK OESs for $\mathrm{H}_{2} \mathrm{~S}$ are based.

5 Bhambhani Y, Burnham R, Snydmiller G, et al. Comparative physiological responses of exercising men and women to $5 \mathrm{ppm}$ hydrogen sulfide exposure. Am Ind Hyg Assoc J 1994;55:1030-5.

6 Bhambhani Y, Burnham R, Snydmiller G, et al. Effects of 5 ppm hydrogen sulfide inhalation on biochemical properties of skeletal muscle in exercising men and women. Am Ind Hyg Assoc J 1996;57:464-8.

7 Bhambhani Y, Burnham R, Snydmiller G, et al. Effects of 10-ppm hydrogen sulfide inhalation on pulmonary function in healthy men and women. J Occup Environ Med 1996;38:1012-17.

8 Bhambhani Y, Burnham R, Snydmiller G, et al. Effects of 10 ppm hydrogen sulfide inhalation in exercising men and women. J Occup Env Med 1997;39:122-9.

9 Lopez A, Prior MG, Yong S, et al. Biochemical and cytologic alterations in the respiratory tract of rats exposed for 4 hours to hydrogen sulfide. Fund Appl Tox 1987;9:753-62.

10 Lopez A, Prior M, Yong S, et al. Nasal lesions in rats exposed to hydrogen sulfide for four hours. Am J Vet Res 1988:49:1 107-1 1.

11 Khan AA, Coppock RW, Schuler MM, et al. Biochemical effects of subchronic repeated exposures to low and moderate concentrations of hydrogen sulfide in Fischer 344 rats. Inhal Tox 1998;10:1037-44

12 Masure R. La kerato-conjunctivite des filatures de viscose: etude clinique et experimentale. Rev Belge de Path 1950;20:287-90.

13 Vanhoorne $M$, de Rouck A, de Bacquer D. Epidemiological study of eye irritation by hydrogen sulphide and/or carbon disulphide exposure in viscose rayon workers. Ann Occ Hyg 1995;39:307-15.

14 Toxigenics Study, 420-0710A-C 1983. 90-Day vapor inhalation toxicity study of hydrogen sulfide in Sprague-Dawley, Fischer F344 and B6C3F 1 mice.

- This is an unpublished study into the effects of repeated exposure in rats and mice.

15 Skrainy B, Reiffenstein RJ, Sainsbury RS, et al. Effects of repeated exposures of hydrogen sulphide on rat hippocampal EEG. Tox Letters 1996;84:43-53.
16 Jappinen P, Vilkka V, Martilla $O$, et al. Exposure to hydrogen sulphide and respiratory function. Br J Ind Med 1990;47:824-8.

17 Richardson DB. Respiratory effects of chronic hydrogen sulphide exposure. Am J Ind Med 1995;28:99-108.

18 Higashi T, Toyama T, Sakurai H, et al. Ind Health 1983;21:281-92.

19 Kilburn KH. Exposure to reduced sulfur gases impairs neurobehavioura function. South Med J 1977;90:997-1006.

20 Kilburn KH, Warshaw RH. Hydrogen sulphide and reduced sulphur gases adversely affect neurolophysiological functions. Tox Ind Health 1995;11:185-97.

21 de Fruyt F, Thiery E, de Bacquer D, et al. Neuropsychological effects of occupational exposure to carbon disulphide and hydrogen sulfide. Int J Occup Environ Health 1998;4:139-46.

22 Hirsch AR, Zavala G. Long term effects on the olfactory system of exposure to hydrogen sulphide. Occup Environ Med 1999:56:284-7.

23 Hayden LJ, Goeden H, Roth SH. Growth and development in the rat during sub-chronic exposure to low levels of hydrogen sulphide. Tox Ind Health 1990;31:45-52.

24 Hannah RS, Hayden L, Roth SH. Hydrogen sulphide alters the amino acid content in developing rat CNS. Neurosci Lett 1989:99:323-7.

25 Health and Safety Executive. EH4O/2002 - occupational exposure limits 2002. London: HSE Books, 2002.

26 Health and Safety Executive. EH64 summary criteria for occupational exposure limits 2002. Hydrogen sulphide - D124. London: HSE, 2002.

\section{QUESTIONS (SEE ANSWERS ON P 270)}

(1) When humans are exposed to $\mathrm{H}_{2} \mathrm{~S}$ indicate which of these statements are true or false:

(a) the odour of $\mathrm{H}_{2} \mathrm{~S}$ is strong, and provides a good warning of dangerously high exposure situations

(b) the phenomenon of "gas eye" occurs following exposure to very low concentrations of $\mathrm{H}_{2} \mathrm{~S}(<10 \mathrm{ppm})$

(c) survivors of high exposures to $\mathrm{H}_{2} \mathrm{~S}$, sufficient to cause brief periods of unconsciousness, may suffer from neurological changes such as memory loss

(d) repeated exposures to $\mathrm{H}_{2} \mathrm{~S}$ have the potential for cause bioaccumulation of sulfide in the body

(2) In terms of toxicological mechanism, which of these statements are true of $\mathrm{H}_{2} \mathrm{~S}$ :

(a) the mechanism of toxicity for $\mathrm{H}_{2} \mathrm{~S}$ is based on it ability to bind avidly to haemoglobin thereby reducing the oxygen carrying capacity of the blood

(b) $\mathrm{H}_{2} \mathrm{~S}$ binds to cytochrome oxidase in mitochondria

(c) $\mathrm{H}_{2} \mathrm{~S}$ can cause a shift to anaerobic metabolism leading to an increased blood lactic acid concentration

(d) there are two mechanisms whereby $\mathrm{H}_{2} \mathrm{~S}$ causes death-depression of the respiratory centres in the brain, and pulmonary oedema

(3) Studies in workers have shown that $\mathrm{H}_{2} \mathrm{~S}$ does not appear to cause impairment of pulmonary function when exposures are controlled in the region of:

(a) $300 \mathrm{ppm}$

(b) $30 \mathrm{ppm}$

(c) $3 \mathrm{ppm}$

(d) $0.3 \mathrm{ppm}$

(4) The following sets of exposure conditions carry at least a $50 \%$ probability of death in either humans or animals:

(a) 10 ppm for 8 hours

(b) 400 ppm for 1 hour

(c) 500 ppm for 4 hours

(d) $2000 \mathrm{ppm}$ for 5 minutes

(5) Which of the following statements are true and which are false:

(a) The UK OESs for $\mathrm{H}_{2} \mathrm{~S}$ are designed primarily to control against non-lethal physiological changes

(b) A STEL was not thought to be necessary for $\mathrm{H}_{2} \mathrm{~S}$ as it does not cause immediate sensory irritation

(c) A "no observed adverse effect level" for $\mathrm{H}_{2} \mathrm{~S}$ was identified in animals at $75 \mathrm{ppm}$

(d) Given that there were human data available, animal data were not used by WATCH in deriving the OESs for $\mathrm{H}_{2} \mathrm{~S}$. 